\title{
Persepsi Ibu Nifas terhadap Pelayanan Kunjungan Nifas
}

\author{
Mother's Perception of the Post Partum Visit Services
}

\author{
Dyah Permata Sari* \\ Program Studi D-III Kebidanan, Sekolah Tinggi Ilmu Kesehatan Majapahit \\ Jl. Raya Gayaman Km. 02 Mojoanyar, Mojokerto, Jawa Timur \\ *Corresponding author: dyahpermatasari86@yahoo.co.id
}

Received: February 15, 2019; Revise: April 15, 2019; Accepted: May 7, 2019

DOI: https://doi.org/10.31001/biomedika.v12i1.383

\begin{abstract}
ABSTRAK
Cakupan pelayanan kunjungan nifas seharusnya lebih besar atau minimal sama dengan target pertolongan persalinan oleh tenaga kesehatan, sebab bidan diharapkan lebih proaktif melakukan kunjungan nifas meskipun terhadap ibu yang persalinannya ditolong oleh dukun. Kenyataannya yang terjadi tentang masalah kunjungan nifas yaitu terjadinya drop out pelayanan antara ibu dengan tenaga kesehatan. Penelitian ini dilakukan untuk menggambarkan persepsi ibu nifas terhadap pelayanan kunjungan nifas. Penelitian ini merupakan penelitian deskriptif. Variabel yang diteliti adalah persepsi ibu nifas terhadap pelayanan kunjungan nifas. Populasi dalam penelitian ini adalah semua ibu nifas di Puskesmas Sooko Kecamatan Sooko Kabupaten Mojokerto yang berjumlah 20 orang. Teknik sampling yang dipergunakan adalah teknik Total sampling. Penelitian dilakukan pada tanggal 11 September - 4 Desember 2018. Instrumen yang digunakan untuk proses pengumpulan data adalah lembar kuesioner,kemudian dilakukan pengolahan data yang meliputi pemeriksaan data, pemberian kode, skor, dan penyusunan data. Hasil penelitian diketahui bahwa hampir seluruhnya responden mempunyai persepsi positif terhadap pelayanan kunjungan nifas. Ditinjau dari usia, tingkat pendidikan, dan jumlah anak responden didapatkan sebagian besar responden berumur antara 20-35 tahun sebanyak 12 responden (60\%). Berpendidikan SMP sebanyak 15 responden $(75 \%)$, dan memiliki 2 anak sebanyak 14 responden (70\%). Persepsi merupakan suatu indikator untuk mengetahui seberapa besar tanggapan responden terhadap suatu objek yang di angkat dalam sebuah penelitian. Hasil penelitian menunjukkan bahwa ibu nifas mempunyai persepsi positif terhadap pelayanan kunjungan nifas. Untuk meningkatkan pelayanan kunjungan nifas sebaiknya dilakukan pengembangan secara kelembagaan.
\end{abstract}

Kata kunci : persepsi; pelayanan kunjungan nifas; ibu nifas

\section{ABSTRACT}

The covered of porturition service supposed to more than or minimal same with chilbirth by the health staff. Because midewife more active doing the porturition call notiwithstanding to toward woman the chilbirth that helping by indigenous medical practitioner. But a matter of fact that happen about the problem of porturition call that is occur a drop out between the women and Health staf. Because that problem that research done to explaint the perception by women of porturion about porturition call service. The kind of this Research are the descriptif research with quantitative 
phenomenological. Variabel that researched are perception by women of porturion about porturition call serve. The Population of this Research are all of the women chilbirth in the Puskesmas Sooko Kecamatan Sooko Kabupaten Mojokerto that amount to 20 people. The technical that used is total sampling. This Research did in September $11^{\text {th }}$ - December $4^{\text {th }}, 2018$. The instrument that used to roundup the file is the kuesioner and the did the processed file that include editing, coding, scoring, tabulating. The result of the Research is almost of the respondent have a positive perception by porturition serve. The observation by age, Education degree, and total of the child, have gotten more of the responden attain the age of 20-35 years old as much as 12 of the respondent (60\%). Well educated of the responden are SMP as much as 15 of the respondent (75\%), and including by total of the child as much as 14 of the responden have 2 child or for about $70 \%$. Perception is the one of the indicator to explaint how much reaction of responden by the object that Raise in the Research. Result of the Research have indicated that women chilbirth have a positive perception about porturition call service. To advance the orturition call service might as well doing the elaboration intitutionaly.

Keyword : perception, porturition call service; childbirth mother

\section{PENDAHULUAN}

Upaya peningkatan kesejahteraan ibu dan janin di dalam kandungan pemerintah berupaya melakukan pendekatan pelayanan kebidanan pada setia ibu hamil, karena itu bidan di Indonesia sangat diperlukan. Pada tahun 1993 WHO merekomendasikan agar bidan dibekali pengetahuan dan keterampilan penanganan komplikasi yang terjadi pada masa nifas. Cakupan kunjungan nifas merupakan perawatan maternal pasca persalinan. Kunjungan nifas sering disama artikan dengan kunjungan neonatus (KN) karena waktunya yang bersamaan dan disingkat sama-sama dengan kunjungan nifas. Cakupan kunjungan nifas seharusnya lebih besar atau minimal sama dengan target pertolongan persalinan oleh tenaga kesehatan, sebab bidan diharapkan lebih proaktif melakukan kunjungan nifas meskipun terhadap ibu yang persalinannya ditolong oleh dukun. Kenyataannya yang terjadi tentang masalah kunjungan nifas yaitu terjadinya drop out pelayanan antara ibu dengan tenaga kesehatan (Edy, 2014)

Kunjungan nifas tingkat Propinsi Jawa Timur pada tahun 2015 sebesar
$77,45 \%$ kisaran rentang antara yang terendah 20,94\% (Kabupaten Pacitan) dengan yang tertinggi 98,75\% (Kabupaten Malang). Bila dibandingkan dengan target kunjungan neonatus Propinsi Jawa Timur tahun 2015 sebesar $80 \%$, maka terdapat 23 dari 35 kabupaten/kota di provinsi Jawa Timur atau $65,71 \%$ yang berhasil mencapai target (Dinkesjatim, 2016).

Pelayanan nifas merupakan pelayanan kesehatan sesuai standar pada ibu mulai 6 jam sampai 42 hari pasca persalinan oleh tenaga kesehatan. Pada masa puerperium ini bidan sebagai tenaga kesehatan sangat mempunyai peran penting serta bertanggung jawab untuk mendeteksi sedini mungkin adanya komplikasi pada ibu serta menyiapkan rujukan jika diperlukan, bidan memberikan Health Education (HE) pada ibu serta keluarganya bagaimana cara mencegah terjadinya perdarahan, mengenal tanda bahaya, mulai dan mendorong ibu untuk memberikan ASI. Bidan memberikan asuhan kebidanan selama masa puerperium dengan melakukan kunjungan rumah, dilakukan pada ketiga, minggu kedua dan minggu keenam setelah persalinan, untuk membantu ibu pada saat 
proses pemulihan serta memperhatikan keadaan bayi terutama pada tali pusat dan juga memberikan penjelasan mengenai masalah kesehatan, kebersihan perorangan, makanan bergizi, perawatan bayi baru lahir, pemberian ASI, imunisasi dan $\mathrm{KB}$ (Ambarwati, 2009). Asuhan pada masa nifas di rumah fakus pada pengkajian, penyuluhan dan HE. Dalam memberikan asuhan kebidanan di rumah, bidan dan keluarga diupayakan dapat berinteraksi dalam suasana yang rileks dan kekeluargaan. Bidan menggunakan keahlian berfikir untuk meningkatkan suatu pilihan perawatan bersama keluarga. Tujuan dari asuhan pada puerperium untuk menjaga kesehatan ibu dan bayinya, baik secara fisik maupun secara psikologis, melakukan skrinning secara komprehensif, mendeteksi dini, mengobati serta merujuk bila terjadi komplikasi pada ibu maupun bayi, memberikan pendidikan kesehatan tentang perawatan kesehatan diri, nutrisi, $\mathrm{KB}$, cara dan manfaat menyusui, pemberian imunisasi serta perawatan bayi sehari-hari, memberikan pelayanan KB dan mendapatkan kesehatan emosi (Ambarwati, 2009).

Sebagai akibat dari diabaikannya kunjungan nifas akan terjadi keterlambatan dalam mendeteksi dan menangani komplikasi pada masa nifas, yang dapat berdampak buruk baik bagi ibu maupun bayinya. Menurut data yang diperoleh dari Dinas Kesehatan Republik Indonesia, 60\% kematian maternal terjadi pada masa nifas dan resiko terbesar kematian bayi baru lahir terjadi pada 24 jam pertama kehidupan, minggu pertama dan bulan pertama kehidupannya. Perilaku dan aspek sosial budaya yang mempengaruhi pelayana kebidanan adalah tradisi-tradisi yang diberlakukan secara turun temurun, misalnya pada saat memberikan makanan bayi, life style (gaya hidup yang berpengaruh terhadap kesehatan) contohnya masyarakat percaya bahwa wanita yang baru melahirkan dilarang bertemu dengan orang lain atau keluar rumah sebelum 40-42 hari setelah melahirkan. Health seeking behavior atau salah satu bentuk perilaku sosial budaya yang mempengaruhi seseorang yaitu apabila seseorang sakit tidak perlu ke pelayanan kesehatan, akan tetapi cukup dengan membeli obat di warung atau mendatangi dukun (Yulifah, 2009)

Berdasarkan studi pendahuluan yang dilakukan pada tanggal 1 September 2018 dengan teknik wawancara pada 5 orang ibu nifas di Puskesmas Sooko Kecamatan Sooko Kabupaten Mojokerto, 3 orang diantaranya mengaku biasa-biasa saja dengan kunjungan nifas yang diberikan oleh bidan setempat dengan alasan, mereka beranggapan setelah melahirkan tidak akan terjadi apa-apa terhadap ibu dan bayinya karena selama proses persalinan tidak terjadi penyulit apapun, dan 2 orang diantaranya mengaku biasa-biasa saja, dengan alasan sudah ada dukun bayi dan nenek yang bisa merawat ibu dan bayinya dan jika salah satu diantaranya sakit mereka cukup membeli obat di apotik.

Kualitas pelayanan yang baik dapat menambah kepercayaan ibu-ibu terhadap tenaga kesehatan. Perlu di ingat, bahwa terjadinya drop out pelayanan karena adanya ketidak percayaan klien terhadap tenaga kesehatan. Untuk dapat menurunkan Angka Kematian Ibu dan Angka Kematian Bayi mau tidak mau harus mendekatkan ibu maternal dengan pelayanan kesehatan atau dengan tenaga kesehatan yang kompeten. Peran bidan di masyarakat merupakan tonggak penting 
untuk membangun sebuah kepercayaan antara pasien dengan tenaga kesehatan. Kemampuan bidan dalam berkomunikasi, berinteraksi dan keterampilan dalam melakukan suatu pelayanan pada klien juga merupakan dasar untuk dapat mengembalikan kepercayaan masyarakat terhadap pelayanan yang diberikan oleh petugas kesehatan (Edy, 2014).

Kunjungan nifas sebagaimana telah dikemukakan diatas dapat dijadikan solusi untuk meningkatkan pelayanan kesehatan di komunitas. Langkah awal supaya pelayanan kunjungan nifas menjadi suatu program berkualitas bagi Puskesmas, maka perlu dikaji sejauh mana persepsi masyarakat khususnya ibu nifas yang berada di Puskesmas Sooko terhadap pelayanan kunjungan nifas. Dengan demikian jaminan pelayanan berkualitas dalam kunjungan nifas akan tercapai.

\section{METODE PENELITIAN}

Jenis penelitian ini adalah jenis deskriptif, dalam penelitian ini menggambarkan persepsi ibu nifas terhadap pelayanan kunjungan nifas Puskesmas Sooko Kecamatan Sooko Kabupaten Mojokerto. Variabel dalam penelitian ini adalah persepsi ibu nifas terhadap pelayanan kunjungan nifas.

Populasi dan Sampel dalam penelitian ini adalah ibu nifas di Puskesmas Sooko Kecamatan Sooko Kabupaten Mojokerto sebanyak 20 orang. Pengambilan sampel yang digunakan dalam penelitian ini adalah non probability sampling dan teknik pengambilan sampelnya memakai total sampling, yang merupakan teknik penentuan sampel di mana semua anggota populasi digunakan sebagai sampel (Sugiyono, 2010). Teknik penentuan sampel ini dipilih karena peneliti mempertimbangkan parameter dari kejadian nifas yaitu 0 hari - 42 hari setelah persalinan, dan juga karena anggota populasinya yang sangat terbatas. Data yang diperoleh dalam penelitian ini meliputi 2 (dua) sumber data yaitu data primer dan sekunder.

Data primer diperoleh dengan menggunakan kuesioner penelitian yang dilengkapi data demografi meliputi usia, tingkat pendidikan, jumlah anak. Kemudian responden diberikan kuesioner tersebut, disertai dengan surat persetujuan menjadi responden. Selanjutnya peneliti menjelaskan maksud dari kuesioner atau pengumpul data kepada responden. Responden yang setuju, maka diberikan waktu 30 menit untuk mengisi dan menandatangani surat persetujuan menjadi responden, serta mengisi kuesioner dengan kesadaran sendiri tanpa paksaan, tidak dipengaruhi oleh orang lain dan benarbenar dari keinginan sendiri.

Data Sekunder diperoleh dari data umum di Puskesmas berupa jumlah ibu nifas di Puskesmas Sooko Kecamatan Sooko Kabupaten Mojokerto yang nantinya akan dijadikan sampel. Alat ukur yang digunakan dalam penelitian ini adalah Kuesioner berupa chek list. Data yang telah dikumpulkan dengan menggunakan lembar kuesioner, kemudian dilakukan pengolahan data yang meliputi

Pemeriksaan Data (Editing), Pemberian Kode (Coding), Skor (Scoring), dan Penyusunan Data (Tabulating) : dengan proses yang meliputi: Mempersiapkan tabel dengan kolom yang barisnya cermat sesuai kebutuhan dan 
menghitung banyaknya frekuensi untuk setiap kategori jawaban nota hasil angket yang telah diisi, ditabulasi dan diberi skor sesuai skala persepsi menurut likert yaitu : 1. Yang menjawab benar atau setuju skor 2 (dua), 2. Yang menjawab mendekati benar atau ragu-ragu (netral) skor 1 (satu), 3. Yang menjawab salah atau tidak setuju skor 0 (nol) (Notoatmodjo, 2010). Adapun untuk menentukan rentang nilai dari kategori menggunakan rumus interval menurut (Budiharto 2008).

$$
\text { Interval }=\frac{\text { Nilai tertinggi }- \text { Nilai terendah }}{\text { Predikat yang diinginkan }}
$$

Dari hasil validitas instrument dengan 16 item pernyataan dengan skor 0 sampai dengan 2 maka interval yang didapatkan pada tiap predikatnya adalah 1 . Persepsi positif : $17-32,2$. Persepsi negatif : $0-$ 16.

\section{HASIL DAN PEMBAHASAN}

Distribusi Frekuensi Responden Berdasarkan Umur. Berdasarkan tabel 1 diperoleh data mengenai usia responden didapatkan sebagian besar responden berumur antara 20-35 tahun sebanyak 12 responden $(60 \%)$.

Tabel 1. Distribusi Frekuensi Responden berdasarkan Umur

\begin{tabular}{cccc}
\hline No & Usia & Frekuensi & Persentasi \\
\hline 1 & $\begin{array}{c}<20 \\
\text { tahun }\end{array}$ & 3 & $15 \%$ \\
\hline 2 & $\begin{array}{c}20-35 \\
\text { tahun }\end{array}$ & 12 & $60 \%$ \\
\hline 3 & $\begin{array}{c}>35 \\
\text { tahun }\end{array}$ & 5 & $25 \%$ \\
\hline Jumlah & 20 & $100 \%$ \\
\hline
\end{tabular}

Distribusi Frekuensi Responden Berdasarkan Pendidikan. Berdasarkan tabel 2 diperoleh data mengenai karakteristik responden berdasarkan pendidikan didapatkan sebagian besar responden berpendidikan SMP sejumlah 15 responden $(75 \%)$.

Tabel 2. Distribusi Frekuensi Responden Berdasarkan Pendidikan

\begin{tabular}{cccc}
\hline No & Pendidikan & Frekuensi & Persentasi (\%) \\
\hline 1 & SD & 3 & 15 \\
\hline 2 & SMP & 15 & 75 \\
\hline 3 & SMA & 2 & 10 \\
\hline & Jumlah & 20 & 100 \\
\hline
\end{tabular}

\section{Distribusi Fekuensi Responden} Berdasarkan Jumlah Anak. Berdasarkan tabel 3 diperoleh data mengenai karakteristik responden berdasarkan jumlah anak didapatkan sebagian besar responden memiliki 2 anak sejumlah 14 responden $(70 \%)$.

Tabel 3. Distribusi Frekuensi Responden Berdasarkan Jumlah Anak

\begin{tabular}{cccc}
\hline No & Jumlah anak & Frekuensi & Persentasi (\%) \\
\hline 1 & 1 Anak & 4 & $20 \%$ \\
\hline 2 & 2 Anak & 14 & $70 \%$ \\
\hline 3 & $>2$ Anak & 2 & $10 \%$ \\
\hline & Jumlah & 20 & 100 \\
\hline
\end{tabular}

Persepsi Ibu Nifas Terhadap Pelayanan Kunjungan Nifas di Puskesmas Sooko Kecamatan Sooko Kabupaten Mojokerto. Berdasarkan tabel 4 didapatkan hampir seluruhnya responden mempunyai persepsi positif yaitu sebanyak 17 responden $(85 \%)$.

Tabel 4.Distribusi Frekuensi Responden Berdasarkan Persepsi Ibu Nifas Terhadap Pelayanan Kunjungan Nifas

\begin{tabular}{cccc}
\hline No & Kriteria & Frekuensi & Persentasi \\
\hline 1 & Positif & 17 & $85 \%$ \\
\hline 2 & Negatif & 3 & $15 \%$ \\
\hline Jumlah & $\mathbf{2 0}$ & $\mathbf{1 0 0} \%$ \\
\hline
\end{tabular}


Berdasarkan tabel 4 tentang Persepsi Ibu Nifas Terhadap Pelayanan Kunjungan Nifas di atas menggambarkan bahwa dari seluruh responden sejumlah 20 orang sebagian kecil responden mempunyai persepsi negatif sebanyak 3 responden (15\%). Hal tersebut dikarenakan peran dukun di masyarakat masih dianggap penting, dalam arti dukun lebih berpengalaman dalam hal perawatan masa nifas. Sebagian besar responden mempunyai persepsi positif terhadap pelayanan kunjungan nifas yaitu sejumlah 17 responden $(85 \%)$. Hal ini terkait dengan pengertian pelayanan kunjungan nifas yaitu kontak ibu nifas dengan tenaga kesehatan minimal 3 kali untuk mendapatkan pelayanan dan pemeriksaan kesehatan ibu nifas, baik di dalam maupun di luar gedung puskesmas termasuk bidan di desa, polindes dan kunjungan rumah yang penatalaksanaan asuhannya diberikan pada pasien dari mulai saat setelah lahirnya bayi sampai dengan kembalinya tubuh dalam keadaan seperti sebelum hamil atau mendekati keadaan sebelum hamil.

Adapun tujuan dari pemberian pelayanan atau asuhan pada masa nifas untuk menjaga kesehatan ibu dan bayinya, baik fisik maupun psikologis, melaksanakan skrinning secara komprehensif, deteksi dini, mengobati atau merujuk bila terjadi komplikasi pada ibu maupun bayi, memberikan pendidikan kesehatan tentang perawatan kesehatan diri, nutrisi, KB, cara dan manfaat menyusui, pemberian imunisasi serta perawatan bayi sehari-hari, memberikan pelayanan keluarga berencana, dan mendapatkan kesehatan emosi (Ambarwati, 2009). Hal ini dapat mendorong ibu nifas sehingga mempunyai persepsi positif terhadap pelayanan kunjungan nifas.

Beberapa faktor-faktor yang mendorong berkembangnya pelayanan kunjungan nifas yaitu : kepedulian masyarakat terhadap kesehatan ibu dan bayi yang sangat tinggi dan juga kepercayaan masyarakat yang masih sangat besar pada tenaga kesehatan khususnya bidan. Sebagian besar ibu nifas beranggapan bahwa mereka lebih senang dirawat oleh bidan karena saran dan anjuran yang diberikan sangat rasional sehingga mudah untuk diterima dan dimengerti oleh ibu nifas Ambarwati. (2008).

Berdasarkan hasil penelitian menurut umur, diketahui bahwa responden yang mempunyai persepsi positif adalah responden yang berumur 20-35 tahun yaitu sebanyak 12 responden (60\%). Menurut Saleha, (2009) menyebutkan ada beberapa faktor yang dapat berpengaruh dalam memperbaiki atau merusak persepsi seorang individu. Secara umum faktorfaktor tersebut terbagi dua, yaitu : faktor internal (kepribadian) individu dan faktor eksternal. Faktor internal meliputi, antara lain; pengalaman, pengetahuan, proses belajar, wawasan pemikiran, keinginan, motivasi dan tujuan. Hal ini sebagai akibat dari pengalaman dan kematangan jiwa. Hal ini bisa dikarenakan pada usia tersebut kemampuan dan kemauan seseorang dalam memperoleh informasi masih cukup tinggi dibandingkan usia di atasnya. Sehingga dari kemampuan dan kemauan tersebut akan mendorong seorang individu untuk berpikir terhadap suatu objek yang ada di sekitarnya. Sehingga dari objek yang berada di sekitarnya tersebut akan 
memunculkan atau menimbulkan suatu persepsi.

Berdasarkan hasil penelitian menurut tingkat pendidikan, didapatkan bahwa responden mempunyai persepsi positif adalah responden dengan tingkat pendidikan SMP yaitu sebanyak 15 responden (75\%). Hal ini disebabkan makin tinggi pendidikan seseorang, maka makin mudah pula dalam menerima informasi sehingga makin banyak pengetahuan yang dimiliki. Pendidikan yang kurang akan menghambat perkembangan seseorang terhadap nilainilai baru yang dikenalkan. Pendidikan seseorang mempengaruhi cara pandangnya terhadap diri dan lingkungannya. Oleh karena akan berbeda sikap seseorang yang berpendidikan tinggi dibandingkan yang berpendidikan rendah, hal ini berhubungan dengan Intelegensi seseorang yang pada prinsipnya mempengaruhi kemampuan penyesuaian diri seseorang yang berintelegensi tinggi akan banyak berpartisipasi dan lebih tepat dan cepat dalam mengambil keputusan. Menurut Saleha, (2009) menyebutkan ada beberapa faktor yang dapat berpengaruh dalam memperbaiki atau merusak persepsi seorang individu. Secara umum faktorfaktor tersebut terbagi dua, yaitu faktor internal (kepribadian) individu dan faktor eksternal. Faktor internal meliputi, antara lain; pengalaman, pengetahuan, proses belajar, wawasan pemikiran, keinginan, motivasi dan tujuan. Hal ini sebagai akibat dari pengalaman dan kematangan jiwa.

Berdasarkan hasil penelitian jumlah anak responden terbanyak adalah memiliki 2 anak yaitu sebanyak 14 responden (70\%) mempunyai persepsi positif. Menurut Saleha (2009), menyebutkan salah satu faktor yang mempengaruhi persepsi adalah faktor fungsional, yaitu persepsi berasal dari kebutuhan pengalaman masa lalu dan hal-hal lain yang termasuk faktor personal, yang menentukan persepsi bukan jenis atau bentuk stimuli tetapi karakteristik orang yang memberikan respons terhadap stimulasi itu. Pengalaman seseorang mempengaruhi cara pandangnya terhadap diri dan lingkungannya. Oleh karena akan berbeda sikap seseorang yang punya pengalaman lebih dibandingkan yang kurang berpengalaman, hal ini berhubungan dengan suatu hal yang pernah di alami atau dirasakan seorang individu sehingga dari pengalaman tersebut dapat memunculkan suatu persepsi. Menurut Saleha (2009), mengemukakan bahwa persepsi adalah suatu pengalaman yang terbentuk berupa data-data yang didapatkan melalui indera, hasil mengolah otak dan ingatan. Proses terjadinya persepsi pada awalnya adalah karena adanya stimulus yang ditangkap oleh panca indera kemudian dibawa ke otak sehingga terbentuk kesan. Dengan adanya pengertian pelayanan kunjungan nifas yang kemudian diorganisasikan dan diinterpretasikan sehingga dapat memberikan arti bagi ibu nifas berupa kebutuhan terhadap pelayanan kunjungan nifas sehingga mempunyai persepsi positif. Lingkup pelayanan dan jenis-jenis pelayanan kunjungan nifas merupakan salah satu bentuk pelayanan kebidanan yang komprehensif. Persepsi pasien dipengaruhi oleh faktor internal berupa keinginan, motivasi dan tujuan serta pengetahuan tentang pelayanan kunjungan nifas dan faktor eksternal yang meliputi lingkungan keluarga, lingkungan fisik, lingkungan kerja dan lingkungan sosial budaya dimana individu tersebut berada. 


\section{KESIMPULAN}

Berdasarkan hasil penelitian dapat disimpulkan bahwa persepsi ibu nifas di Puskesmas Sooko Kecamatan Sooko Kabupaten Mojokerto terhadap pelayanan kunjungan nifas didapatkan hasil bahwa sebagian besar ibu nifas mempunyai persepsi positif terhadap pelayanan kunjungan nifas,yaitu sebanyak 17 responden $(85 \%)$.

\section{DAFTAR PUSTAKA}

Ambarwati. 2008. Asuhan Kebidanan Nifas. Yogyakarta: Mitra Cendikia

Ambarwati. 2009. Asuhan Kebidanan Komunitas. Yogyakarta: Nuha Medika

Borneo, Konsep Nifas, Eklamsi, Forceps, (http://id.google.com/Konsep nifas diakses 13 Desember 2018 : 20.00 WIB.

Budiharto. 2008. Metodologi Penelitian Kesehatan dengan Contoh Bidang Ilmu Kesehatan GIGI. E-book. www.books.google.co.id/
Dinkesjatim, 2016. Profil Data Kesehatan Indonesia Tahun 2016. Kementerian Kesehatan Republik Indonesia.

Edy. 2014. Sikap manusia teori dan pengukurannya. Yogyakarta: Pustaka Belajar.

Hidayat. 2007. Metodologi Penelitian Keperawatan dan Teknik Analisis Data. Jakarta: Salemba Medika

Maryunani. 2009. Perawatan Masa Nifas (Post Partum). Yogyakarta: Fitramaya

Notoatmodjo. 2007. Pendidikan dan perilaku kesehatan. Jakarta: Rineka cipta

Notoatmodjo. 2010. Metodologi Penelitian Kesehatan. Jakarta: Rineka Cipta.

Nursalam. 2009. Konsep dan penerapan metodologi penelitian ilmu keperawatan: pedoman skripsi, tesis dan instrumen penelitian. Jakarta: Salemba Medika.

Saleha, S. 2009. Asuhan Kebidanan Pada Masa Nifas. Jakarta: Salemba Medika.

Sugiyono. 2009. Metode penelitian kuantitatif, kualitatif dan $R$ \& D. Bandung: Alfabeta.

Sugiyono. 2010. Statistika Untuk Penelitian. Bandung: Alfabeta.

Suherni. 2008. Perawatan Masa Nifas. Yogyakarta: Fitramaya.

Yulifah, R. (2009). Asuhan Kebidanan Komunitas. Jakarata: Salemba Medika. 